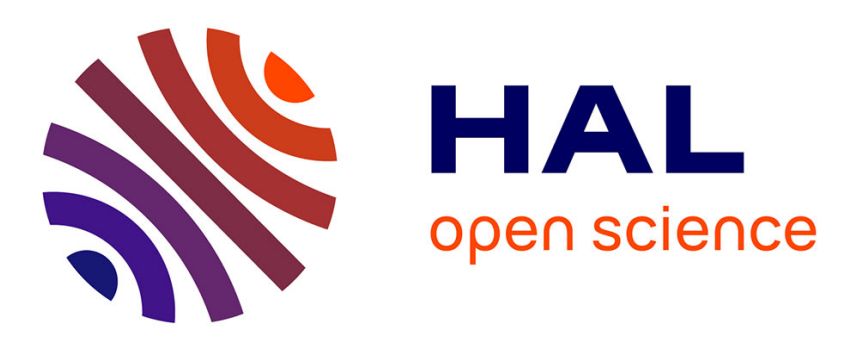

\title{
Voltage-gated sodium channel organization in neurons: Protein interactions and trafficking pathways
}

Christophe Leterrier, Anna Brachet, Marie-Pierre Fache, Bénédicte Dargent

\section{To cite this version:}

Christophe Leterrier, Anna Brachet, Marie-Pierre Fache, Bénédicte Dargent. Voltage-gated sodium channel organization in neurons: Protein interactions and trafficking pathways. Neuroscience Letters, 2010, 486 (2), pp.92-100. 10.1016/j.neulet.2010.08.079 . hal-01701555

\section{HAL Id: hal-01701555 \\ https://hal.science/hal-01701555}

Submitted on 20 Apr 2018

HAL is a multi-disciplinary open access archive for the deposit and dissemination of scientific research documents, whether they are published or not. The documents may come from teaching and research institutions in France or abroad, or from public or private research centers.
L'archive ouverte pluridisciplinaire HAL, est destinée au dépôt et à la diffusion de documents scientifiques de niveau recherche, publiés ou non, émanant des établissements d'enseignement et de recherche français ou étrangers, des laboratoires publics ou privés. 
Review

\title{
Voltage-gated sodium channel organization in neurons: Protein interactions and trafficking pathways
}

\author{
Christophe Leterrier $^{\mathrm{a}, \mathrm{b}}$, Anna Brachet ${ }^{\mathrm{a}, \mathrm{b}}$, Marie-Pierre Fache ${ }^{\mathrm{a}, \mathrm{b}}$, Bénédicte Dargent ${ }^{\mathrm{a}, \mathrm{b}, *}$ \\ a INSERM UMR 641, Marseille F-13916, France \\ b Université de la Méditerranée, Faculté de Médecine Secteur-Nord, Institut Fédératif de Recherche 11, Marseille F-13916, France
}

\section{A R T I C L E I N F O}

\section{Article history:}

Received 4 June 2010

Received in revised form 27 July 2010

Accepted 26 August 2010

\section{Keywords:}

Voltage-gated sodium channels

Nav

Axon initial segment

Nodes of Ranvier

Trafficking

Targeting

\begin{abstract}
A B S T R A C T
In neurons, voltage-gated sodium (Nav) channels underlie the generation and propagation of the action potential. The proper targeting and concentration of Nav channels at the axon initial segment (AIS) and at the nodes of Ranvier are therefore vital for neuronal function. In AIS and nodes, Nav channels are part of specific supra-molecular complexes that include accessory proteins, adhesion proteins and cytoskeletal adaptors. Multiple approaches, from biochemical characterization of protein-protein interactions to functional studies using mutant mice, have addressed the mechanisms of Nav channel targeting to AIS and nodes. This review summarizes our current knowledge of both the intrinsic determinants and the role of partner proteins in Nav targeting. A few fundamental trafficking mechanisms, such as selective endocytosis and diffusion/retention, have been characterized. However, a lot of exciting questions are still open, such as the mechanism of differentiated Nav subtype localization and targeting, and the possible interplay between electrogenesis properties and Nav concentration at the AIS and the nodes.
\end{abstract}

(c) 2010 Elsevier Ireland Ltd. All rights reserved.

\section{Contents}

1. Introduction.

2. Structure, function and localization of the Nav channels ...

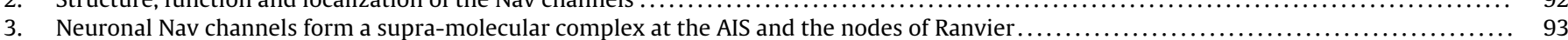

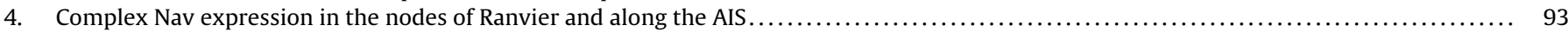

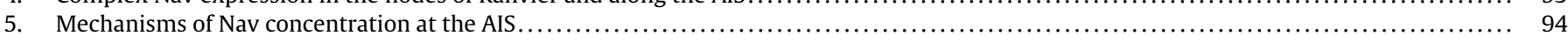

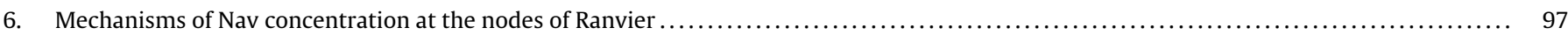

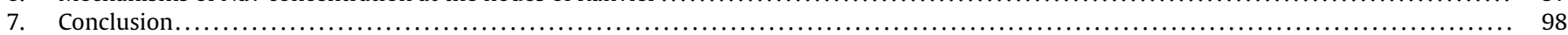

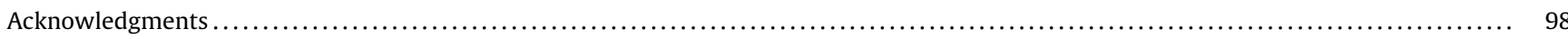

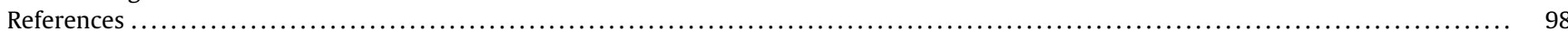

\section{Introduction}

In neurons, action potentials (APs) are generated at the axonal initial segment (AIS), and their saltatory conduction occurs via the nodes of Ranvier in myelinated axons $[15,46]$. These processes require a precise distribution of voltage-gated sodium (Nav) channels, which accumulate at high density in these two highly specialized axonal sub-domains. This concentration of Nav channels results from the assembly of supra-molecular complexes composed

\footnotetext{
* Corresponding author at: Faculté de Médecine Secteur-Nord, Neurobiologie des Canaux ioniques, Université de la Méditerranée CS80011, Bd Pierre Dramard, 13344 Marseille Cedex 15, France. Tel.: +33 4916988 59; fax: +33 491090506.

E-mail address: benedicte.dargent@univmed.fr (B. Dargent).
}

of numerous partners, such as adhesion proteins and cytoskeletal adaptors. This review aims to summarize the different partners of Nav channels at the AIS and nodes, and recapitulate their roles in Nav targeting to these compartments. The basic mechanisms of the specific targeting of Nav channels have been unravelled using a combination of biochemical, cellular and functional studies. However, many more questions need to be answered to fully explain Nav targeting and its importance for neuronal transmission in normal and pathological contexts.

\section{Structure, function and localization of the Nav channels}

Mammalian Nav channels are composed of a highly glycosylated $260 \mathrm{kDa} \alpha$ subunit, the pore forming protein, linked via disulfide bonds to $\beta 2 / \beta 4$ subunits and non-covalently with $\beta 1 / \beta 3$ subunits 
[11]. Nine Nav1 $\alpha$ subunit genes (SCN1A-SCN9A) have been identified in mammals, constituting the Nav1 gene subfamily. The Nav subunits (Nav1.1-9) contain the ion-selective pore and are composed of 4 homologous membrane domains (I-IV) containing 6 transmembrane $\alpha$ helices (S1-S6). S5 and S6 segments from the four domains form the $\mathrm{Na}^{+}$selective pore, and the $\mathrm{S} 4$ helix acts as a voltage sensor whose movement within the membrane induces in pore opening [11].

$\beta$ subunits $(\beta 1-4)$ are encoded by four different genes (SCN1B-SCN4B). The $\beta$ subunits share a similar topology, and their structure-function has been reviewed by Patino and Isom in this special issue [63]. $\beta$ subunits regulate the surface density of Nav1 and modulate the biophysical properties of the channel in complex and opposite ways [67]. In addition, the $\beta$ subunits exhibit CAM properties, being involved in multiple interactions through either homophilic or heterophilic interactions with members of the L1 CAM family [56], and recognizing molecules in the extracellular matrix (ECM, [80]). Finally, the $\beta 1$ subunit promotes neurite outgrowth in cerebellar granule cells (GCs) via a lipid raft mechanism and Fyn kinase signaling $[7,8,20]$.

With the exception of Nav1.4, all Nav1 subunits are expressed in the nervous system. Nav1.1, Nav1.2 and Nav1.6 are abundant in the central nervous system (CNS), whereas Nav1.3 is mostly present during embryonic development. Nav1.7, Nav1.8 and Nav1.9 are predominant in the peripheral nervous system (PNS) [11]. $\beta 1$, $\beta 2$ and $\beta 4$ are the main $\beta$ subunits expressed in the mammalian brain [63]. Both the expression of the four predominant Nav1 subtypes and the four $\beta$ subunits are developmentally and spatially regulated in the CNS (for a review see [84]). At the cellular level, Nav1.1 is predominantly found not only in soma and dendrites but also at the AIS and nodes of Ranvier [23,33,90]. Nav1.2 is localized along unmyelinated axons and accumulates at the AIS and in immature nodes $[4,5,33,53,90]$. Nav1.6 is concentrated in the AIS, nodes of Ranvier and in proximal dendrites in many types of neurons $[10,53]$. In contrast, little information is available on $\beta$ subunit localization at the cellular level, although $\beta 2$ may be concentrated at the nodes of Ranvier [13] and $\beta 1$ has been detected at the AIS in cerebellar GCs [7].

\section{Neuronal Nav channels form a supra-molecular complex at the AIS and the nodes of Ranvier}

In neurons, Nav channels concentrate at the AIS and nodes of Ranvier as part of well-described multi-molecular complexes [35] (Fig. 1A). In addition to Nav channels, potassium channels Kv7.2/Kv7.3 [21,62] and cell adhesion molecules NF-186 and $\operatorname{NrCAM}[2,19,24,36]$ accumulate at the AIS and the nodes of Ranvier where the cytoskeletal adaptor complex ankyrin $G(\operatorname{ankG}) / \beta 4$ spectrin is segregated [98] (for reviews see [3,75], Fig. 1B). The AIS and the nodes of Ranvier are also enriched in other proteins, such as protein kinase casein kinase 2 (CK2) which regulates ion channel interaction with ankG [9], SCHIP-1 isoforms [55], FHF2 and FHF4, two members of the fibroblast growth factor homologous factors (FHFs, [32]) and members of the NFKB signaling pathway [66,77]. Lastly, in certain neuronal types, members of the Kv1 voltage-gated potassium channel family are restricted to the distal part of the AIS $[39,52]$.

These supra-molecular complexes at the AIS and nodes are the result of multiple, redundant protein-protein interactions, Nav channels being a core component in this interaction network (Fig. 1C). A key partner of Nav channels is ankG. A well-characterized ankyrin-binding motif is located in the cytoplasmic linker II-III of the pore forming Nav1 protein [26,31,51] (see below). It is possible that $\beta 1$, but not $\beta 3$, provides an additional link between Nav channel complex and ankG since homophilic $\beta 1$ sub- unit interaction induces ankG recruitment [7,54]. In addition, $\beta 1$ subunits interact heterophilically with NF-186 and NF-155, NrCAM [56] and contactin/F3, a CAM protein concentrated in the nodal and paranodal regions of CNS nodes [44]. Nav1 and $\beta 1$ subunits associate with the receptor protein tyrosine phosphatase $\beta$, a partner of contactin/F3 [69]. The $\beta 2$ subunit binds to tenascin- $C$ and tenascin$\mathrm{R}$ [80,93], two ECM molecules that associate with brevican [58]. Finally, studies have shown that several members of the FHF family interact and differentially modulate the functional properties of Nav1 [92]. Furthermore, some of FHF members are enriched at the AIS and influence Nav channel clustering $[32,49]$.

\section{Complex Nav expression in the nodes of Ranvier and along the AIS}

Initial studies of Nav1 subunit localization in mammalian brain showed that Nav1.2 is preferentially expressed along unmyelinated fibers [33,90] while Nav1.6 is localized at nodes of Ranvier [10]. Boiko et al. [4] confirmed the differential localization of Nav1.2 and Nav1.6 in retinal ganglion cells (RGCs) that form axons with well defined unmyelinated and myelinated segments. During development, a switch between Nav1.2 and Nav1.6 expression occurs in RGCs axons; Nav1.2 is first concentrated at the immature nodes of Ranvier and is replaced by Nav1.6 as the nodes mature [4]. Complemented by others studies [72], Nav1.6 channels have thus been considered predominant in mature nodes of Ranvier (for a review see [84]). However, at present, the situation appears to be more complex. Indeed, Nav1.6 is expressed alone or together with Nav1.1 in CNS and PNS nodes of Ranvier [23]. Moreover, nodes of Ranvier expressing Nav1.1, but not Nav1.6 have been described [23]. The developmental expression of Nav1.1, Nav1.2 and Nav1.6 at the nodes of spinal cord neurons indicates that these three channels can coexist at certain stages of nodal maturation [23]. Finally, Nav1.8, a subtype preferentially expressed in sensory neurons [11], were observed at nodes of Ranvier in physiopathological situations $[1,22]$.

Studies also provide evidence for a complex and cell specific subdomain organization of Nav1 types along the AIS, with spatially and temporally defined co-expression of Nav1.6, Nav1.1 and Nav1.2. Firstly, Nav1.6 is exclusively and uniformly distributed along the AIS of Purkinje cells [52,85]. Nav1.6 is expressed together with Nav1.1 in the AIS in cortical and cerebellar interneurons, in RGCs and in spinal cord neurons $[23,52,60,87]$. In these cells, Nav1.1 and Nav1.6 showed a complementary localization along the AIS: Nav1.1 displays a proximo-distal gradient along the AIS, whereas Nav1.6 accumulates in a distal-to-proximal gradient $[5,23,86]$. In contrast, Nav1.1 and Nav1.6 are uniformly co-distributed along the AIS of main olfactory bulb short axon cells [52]. Nav1.2 is co-expressed with Nav1.6 in layer 5 pyramidal cells of the neocortex with a complementary gradient of Nav1.2-Nav1.6 concentration along the AIS [38]. Importantly, Nav1.6 accumulation at the distal AIS determines the lowest threshold for AP initiation whereas a proximal Nav1.2 gradient promotes AP back propagation to the soma [38]. Nav1.2 and Nav1.6 are also co-expressed along the AIS of cerebellar GCs [61].

During development, Nav1.2 accumulation precedes Nav1.6 concentration in RGCs and in GCs [5,61]. Mice lacking Nav1.6 (Scn8a $a^{\text {medJ }}$ mice) exhibit distinct compensatory change in other Nav1 types. Both Nav1.1 and Nav1.2 compensate the lack of Nav1.6 at the AIS of RGCs while only Nav1.1 replaces Nav1.6 at the AIS of cerebellar Purkinje cells [85], but no compensatory expression between Nav1.6 and Nav1.1 was observed at the AIS in GCs-specific Nav1.6-null mouse [61]. Such a complex organization and regulation of Nav1 types at the AIS is expected to endow neurons with variable excitability properties, which can influence the genera- 

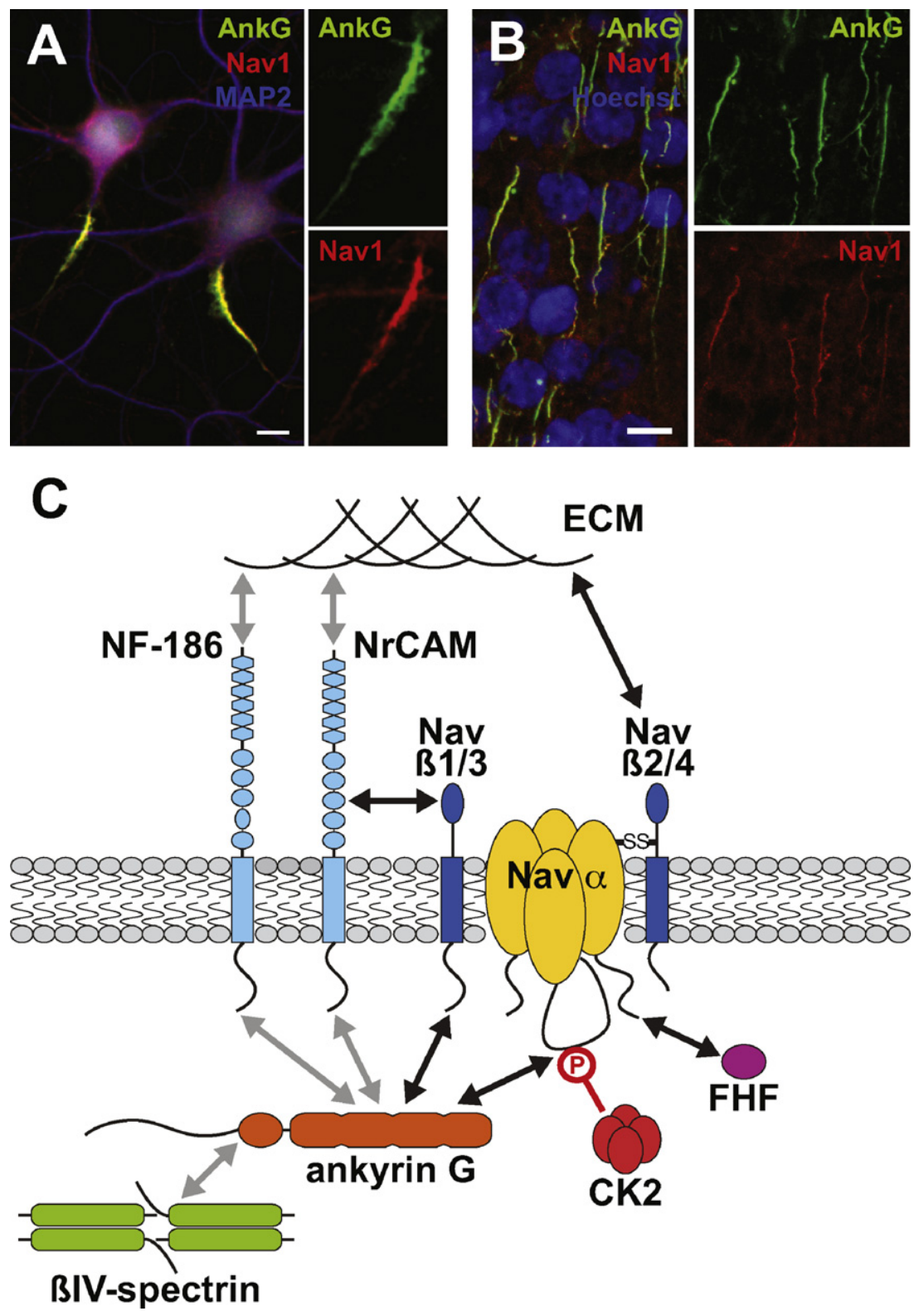

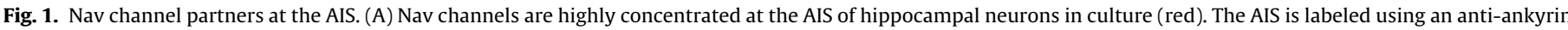

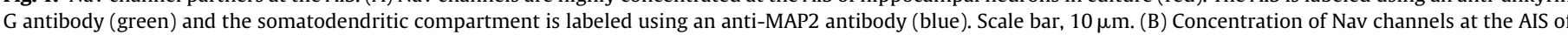

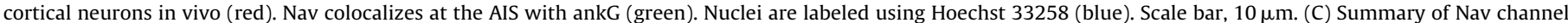

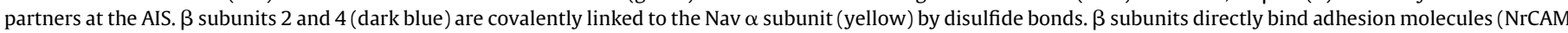

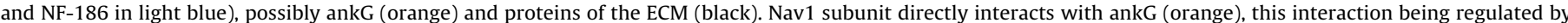

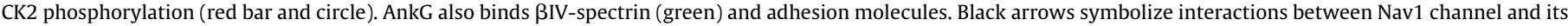
direct partners; grey arrows represent interaction between Nav1 partners.

tion and the backpropagation of APs [15,38]. Further studies are required for a better understanding of mechanisms accounting for such complex nodal expression and of the respective physiological relevance of each expression pattern.

\section{Mechanisms of Nav concentration at the AIS}

The AIS is intrinsically specified, being able to assemble in cultured neurons in the absence of glial cells $[91,97]$. In vivo and in vitro analyses all converge on a crucial role of ankG as the central organizer for AIS assembly and maintenance [36,40,98]. ankG is the first component detected at the AIS by immunohistochemistry [40]. In vivo, mutant mice lacking ankG in Purkinje cells fail to cluster any other AIS component $[40,98]$, and electroporation of cortical neurons with shRNA against ankG blocks AIS assembly [36]. In cultured hippocampal neurons, knockdown of ankG impedes AIS formation while knockdowns of CAMs, Nav channels or $\beta 4$-spectrin have little impact [36]. ankG is an essential organizer of the AIS as Nav, Kv7.2/7.3 channels, CAMs and $\beta 4$-spectrin all rely on binding to ankG for their localization $[31,51,62,96]$.

A role for Nav channels in AIS formation and maintenance is, however, not excluded. In cultured motor neurons, Xu and Shrager demonstrated that the decrease of Nav channel expression affects AIS assembly, suggesting that a complementary mechanism might exist in this cell type [94]. In vivo confirmation of the possible role of Nav in AIS assembly may prove difficult, because of the perinatal lethality of the Nav1.2 knockout mouse [64] and the compensation for Nav1.6 loss by Nav1.2 and Nav1.1 in the Scn8amedJ mouse [85]. 
The role of Nav $\beta$ subunits in Nav channel targeting to the neuronal membrane is not fully understood. Tagged $\beta$ subunits expressed in cultured hippocampal neurons are uniformly distributed [30], indicating that Nav $\alpha$ rather than $\beta$ subunits may contain information for the sorting and clustering of Nav channel complexes at the AIS. However, cerebellar neurons lacking $\beta 1$ show a decreased concentration of Nav 1.6 at the AIS [7]. Therefore, similarly to $\beta 4$-spectrin $[45,48], \beta$ subunits could be necessary for the maintenance of Nav channel complexes at the AIS rather than for their initial concentration at this site.

The key interaction for AIS assembly and function, that is, the binding of Nav channels to ankG, was discovered more than twenty years ago [81]. However, the molecular details of this interaction and its role in Nav channel concentration at the AIS were only recently unravelled $[9,26,31,37,51]$. To assess whether any of the intracellular loops of Nav1.2 contained sufficient information for its sorting to the AIS, our laboratory developed an approach based on chimeric protein expression in cultured hippocampal neurons [29]. Using this approach, we showed that the cytoplasmic loop linking the domains II and III (L2) contained a motif responsible for the compartmentalization of Nav channels at the AIS (Fig. 2B and C) [31]. L2 was sufficient to either segregate a chimera of the CD4 protein (CD4-Nav1.2) at the AIS, or redirect the somatodendritic potassium channel Kv2.1 (Kv2.1-Nav1.2). This targeting was abolished upon truncation of a sequence of 27 residues within L2 (1102-1128) that was thus called the AIS motif (Fig. 2A) [31]. Another study independently confirmed that the PIALGESD sequence located within the AIS motif directly interacts with the Membrane Binding Domain (MBD) of ankG [51].

ankG is segregated at the AIS, whereas the other neuronal ankyrin, ankyrin B, is located along the distal axon in cultured hippocampal neurons and in myelinated fibers [3]. These axonal ankyrins share a highly conserved MBD, suggesting that an additional mechanism must ensure the specific interaction of Nav

\section{A}

Nav $1.2{ }^{1097}$ nnpsI T V T V P I A L G E S D F E N L N T E E F S SE S D M eeske ${ }^{1133}$
Nav 1.1 ${ }^{1107}$ nnpsI T V T V P I A V G E S D F E N L N T E D F S S E S D Leeske ${ }^{1143}$
Nav 1.3 ${ }^{1046}$ nnpsI T V T V P I A V G E S D F E N L N T E E F S S E E Leeske ${ }^{1082}$
Nav 1.6 ${ }^{1086}$ nnpnl T V R V P I A V G E S D F E N L N T E D VS S E D P egskd ${ }^{1122}$
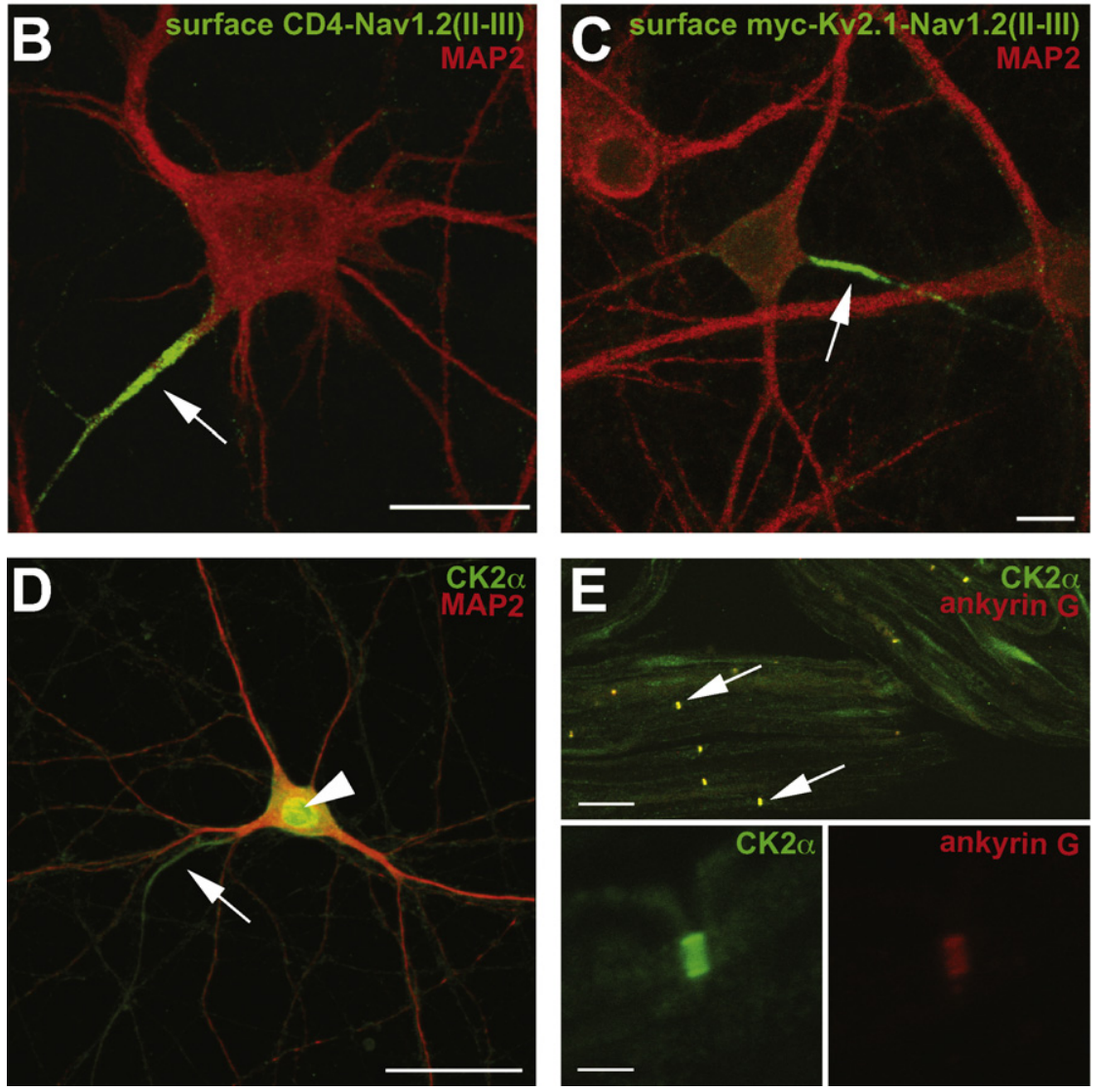

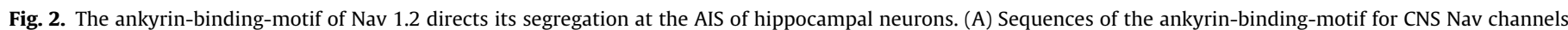

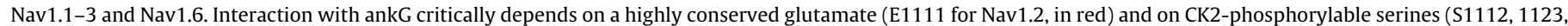

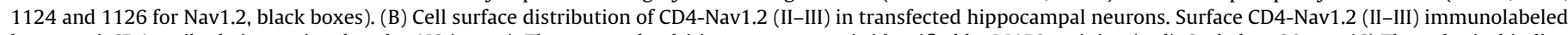

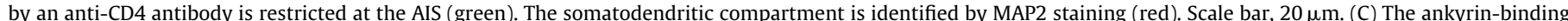

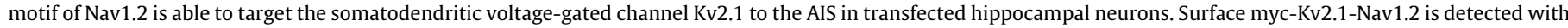

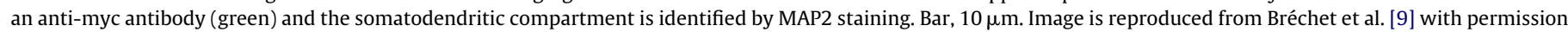

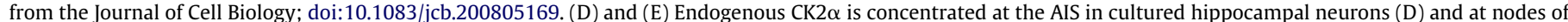

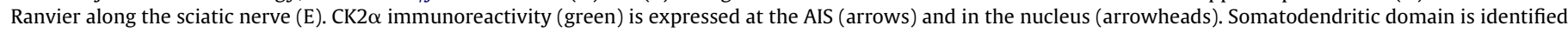

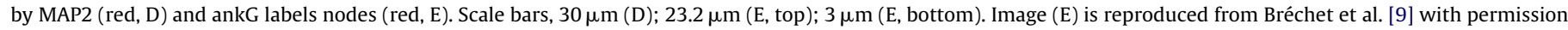
from the Journal of Cell Biology; doi:10.1083/jcb.200805169. 
channels with ankG. Recently, Bréchet et al. demonstrated that the AIS motif of neuronal Nav channels is phosphorylated in vitro by CK2, resulting in a 1000-fold increase in the binding affinity (from micromolar to nanomolar) for the MBD of ankG [9]. Although CK2 phosphorylation equally enhanced the interaction with the MBD of ankyrin B and G [9], they showed that CK2 appears to be exclusively concentrated at the AIS and nodes along the axon (Fig. 2D and $\mathrm{E}$ ). This suggests that local concentration of CK2, which phosphorylates Nav channels, enhances their interaction with ankG, and thus contributes to their specific accumulation at the AIS. Now it would be interesting to identify the phosphatase counterbalancing CK2 phosphorylation that could fine-tune this regulation. In addition to its pivotal role in Nav accumulation, ankG modu- lates the inactivation properties of $\mathrm{Na}^{+}$current in heterologous cells [79], but the electrophysiological consequences of a phosphodependant binding of ankG remains to be explored in neurons. Another unresolved issue is that Nav1.1, Nav1.2 and Nav1.6 bear CK2 phosphorylation sites at their AIS motif, but they are differentially expressed during development at the AIS [5,61], and exhibit distinct subdomain organization along the AIS in defined neuronal types $[38,52,87]$. Additional mechanisms probably account for this preferential organization. Nevertheless, the discovery of a CK2-dependent Nav-ankG interaction suggests that CK2 can dynamically alter Nav concentration at the AIS. Thus, CK2 could play a role in the activity-driven AIS plasticity that was recently described [34,47].
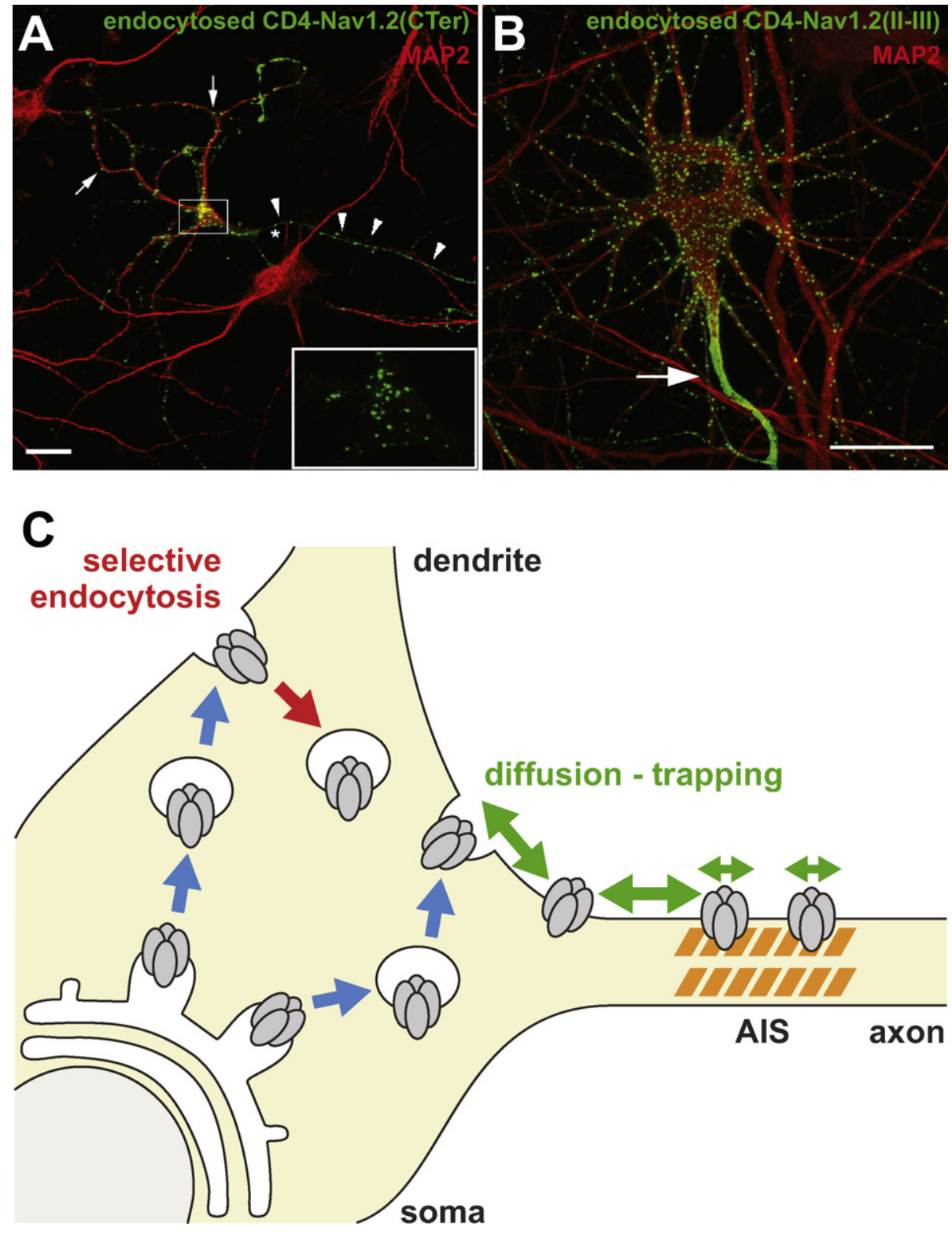

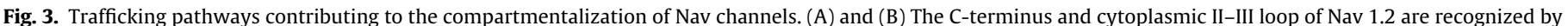

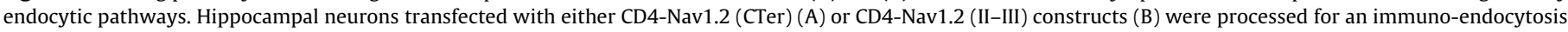

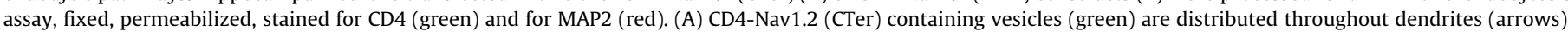

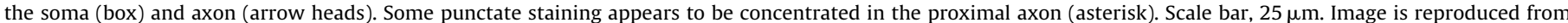

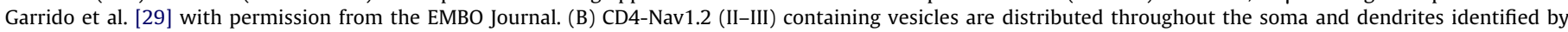

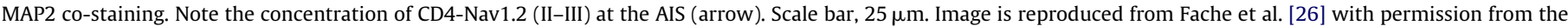

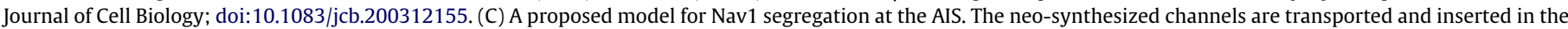

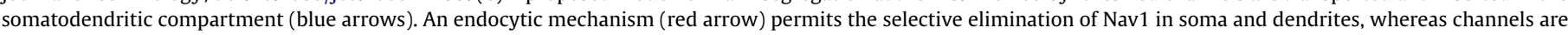

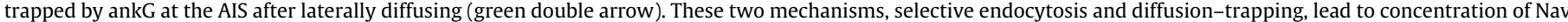
channels at the AIS. 
Beyond the interaction of Nav and ankG at the AIS, two general models may underlie the final compartmentalization of Nav channels at the AIS: (i) the channels could be directly inserted in the AIS plasma membrane from biosynthetic vesicles and/or (ii) the channels could be initially transported and uniformly inserted in the neuronal membrane, subsequently retrieved from the dendrites, soma and the distal axon by endocytosis, while being tethered by ankG at the AIS (elimination/retention model). These two models could coexist and their relative importance may vary with the neuronal developmental stage.

We first showed that endogenous Nav channels could undergo activity-dependent endocytosis in developing neurons $[17,18]$. Garrido et al. [29] further demonstrated that chimeric proteins bearing the carboxy-terminal tail of Nav1.2 channels were concentrated at the axonal plasma membrane in dissociated hippocampal neurons. This compartmentalization arises from the selective endocytosis of the chimera in the somatodendritic compartment (Fig. 3A), suggesting that Nav channels are addressed to the axon via an elimination/retention model. Finally, the determinants in L2 of Nav1.2 are sufficient to target a chimeric protein to the AIS by an elimination/retention mechanism [26]. Sodium channel L2 actually contains two determinants, the AIS motif responsible for the ankG tethering and an endocytic signal located more distally in the loop. Fache et al. [26] showed that CD4-Nav1.2 is first inserted in the somatodendritic compartment and distal axon, before being endocytosed from these sites and restricted to the AIS (Fig. 3B). In view of these findings, we propose that in developing neurons, Nav channels are first uniformly inserted in the neuronal plasma membrane, including soma and dendrites. Channels would then diffuse laterally until they are endocytosed or trapped by ankG when they reach the AIS (Fig. 3C). Consistent with this scenario, the presence of a conserved binding site for Nedd 4 and Nedd $4-2$ ubiquitin ligases in the C-terminus of several Nav1 subunits could target endocytosed channels to degradative pathways [28]. The key ankyrin-binding and endocytosis motifs are conserved between neuronal Nav subunits (Nav1.1-3 and Nav1.6), and the known localization for these subunits includes AIS and nodes [84]. However, the fact that Nav 1.1 and Nav 1.6 have also been detected in other compartments such as soma, dendrites and synapses [84] suggest that other motifs and/or partner proteins can overcome these mechanisms in some neuron types.

The fact that Nav channels are able to concentrate at the AIS due to their interaction with ankG implies that the AIS is a diffusion trap for these proteins. A decreased diffusion of Nav channels-bound toxins at the axon hillock has been described [59], and confirmed by recent data obtained in our laboratory using single particle tracking of quantum-dot labeled ion channels [6]. Brachet et al. [6] show that the ion channel chimera Kv2.1-Nav1.2 diffuses slowly at the AIS membrane and that this immobilization depends on its ability to bind ankG. Moreover, consistent with a role of phosphorylation increasing the binding affinity of Nav to ankG, inhibition of CK2 enhances Kv2.1-Nav1.2 diffusion and impacts Nav channels accumulation at the AIS. As CK2 can directly modulate ion channel chimera mobility at the AIS, it would be very interesting to test if activity-dependent Nav phosphorylation by CK2 can modulate excitability by altering Nav channels mobility and localization at the AIS.

\section{Mechanisms of Nav concentration at the nodes of Ranvier}

The molecular architecture of the nodes of Ranvier is strikingly similar to that of the AIS, with a concentration of Nav channels and adhesion proteins tightly anchored to an ankG/ $\beta 4$-spectrin submembrane cytoskeleton [75]. However, the presence of myeli- nating cells (Schwann cells or oligodendrocytes) and their complex relationship with nodal region organization leads to crucial differences in the mechanism of nodes formation and maintenance [82]. Additionally, nodes of Ranvier can be very far from the soma, and trafficking mechanisms allowing for delivery and concentration of Nav channels at such distal locations are yet to be unravelled.

In the PNS, the main steps of node formation have now been delineated [76]. Immunocytochemistry studies have shown that nodes are first formed, followed by delineation of paranodes and juxtaparanodes [57,65]. At the node itself, initial results suggest an extrinsic mechanism initiated by glial cells [14], with recruitment of adhesion proteins occurring before ankG and Nav concentration [50]. Later in vitro studies have detailed the sequence of events leading to node formation. Schwann cells secrete gliomedin, an oligomeric ligand that recruits NF-186 to nascent nodes [25]. NF186 is then recruits ankG to nodes, which in turn recruits Nav channels [24] and $\beta 4$-spectrin [96]. This sequence of events, and the prominent role of NF-186 in node assembly, is confirmed by the general absence of nodes in the PNS of NF-186 knockout mice [78]. Mice deficient for nodal components not directly involved in node assembly such as NrCAM [16] and $\beta 4$-spectrin $[45,48,95]$ also exhibit altered nodes, demonstrating the interdependence of every nodal component for long-term nodal maintenance.

The mechanism of node formation in the CNS is much less well understood, in part because of the lack of practical in vitro models. As gliomedin is absent in the CNS, it has been proposed that a redundant network of ECM proteins such as brevican, versican and tenascin-R are responsible for the initiation of NF-186 recruitment [82]. Notably, clustering of Nav channels can be induced in RGC cultures by an unidentified soluble factor released by oligodendrocytes [43]. However, the requirement for NF-186 is not as absolute as in the PNS [99]. Other intriguing results have been reported relative to node formation in the CNS: concentration of paranodal components occurs before nodal ones [68], and ankG clusters can appear before adhesion proteins at the optic nerve nodes [41]. This suggests the presence of complementary or alternative mechanisms directing the assembly of CNS nodes [82].

In contrast to the AIS, this mechanism places ankG and Nav channels as downstream participants in nodes formation. The effect of ankG absence at nodes in vivo is unknown, as the cerebellar ankG knockout model still exhibit ankG labeling at nodes of Ranvier [40]. In myelinating DRG cultures however, knockdown of ankG in neurons abolishes node formation, including NF-186 clustering, indicating a central role for ankG in maintaining the integrity of the nodal complex [24]. Although CK2 is concentrated at the nodes of Ranvier in the CNS and PNS [9], whether it directly regulates the ankyrin-Nav interaction at nodes has not been determined yet.

Nav $\beta$ subunits are also present at the nodes $[12,13,42,70]$, and NF-186 and Nav $\beta$ subunits can interact in cis [70], suggesting an alternative mechanism for Nav channel recruitment to the nodes through $\beta$ subunits. In support to this, mice deficient for Nav $\beta 1$ show defects in nodal architecture, and both $\beta 1$ and $\beta 2$ knockout mice exhibit altered nerve conduction characteristic of a reduced Nav channel density $[12,13]$. However, it is likely that $\beta$ subunits are involved primarily in Nav cluster maintenance rather than formation, as a NF-186 mutant deficient in ankyrin binding but capable of binding $\beta$ subunits fails to cluster Nav channels at nodes in vitro [24]. Nav $\alpha$ subunits by themselves probably play a role in the node maintenance, as Scn8a $8 a^{\text {medj }}$ mice lacking Nav1.6 exhibit elongated, disorganized nodes [71], even if sustained expression of Nav1.2 and Nav1.1 compensate for the lack of Nav1.6 [85,88]. Furthermore, the effect of a knockdown of Nav channels at nodes by shRNA, in vitro or in vivo, is still unknown.

It is likely that nodal membrane proteins are directly inserted into the node, although this has not been demonstrated yet. A critical role of paranodal junctions in limiting subsequent diffu- 
sion of nodal membrane proteins, in particular Nav channels, was proposed thirty years ago [73]. Consistent with this hypothesis, different mouse models with altered paranodal junctions have longer and more diluted clusters of Nav channels [72,74,83]. Restriction of nodal components diffusion by paranodes has been proposed as an additional mechanism of Nav channel clustering in the CNS $[68,99]$ and in the PNS [27]. The internode region, where the axonal membrane is apposed to glial cells, has long been thought to be passive with respect to nodal component clustering, but recent studies have shown that it actively directs Nav channels toward the nodes [89]. Direct studies of Nav channel diffusion by live-cell imaging techniques in myelinating cultures would be instrumental to characterize the restriction of diffusion at nodes and the role of paranodes.

Strikingly, paranodal junctions seem to have a prominent role in the differential expression of Nav1.2 and Nav1.6 types at nodes $[4,72]$. Mice with altered paranodes exhibit incomplete replacement of Nav1.2 by Nav1.6 in PNS nodes [72,83]. The fact that Nav1.2, but not Nav1.6, can cluster to form immature nodes in RGC cultures treated with oligodendrocytes-conditioned medium [42] further suggests that myelinating cells could direct the differential targeting of the two Nav $\alpha$ subunits at the nodes.

\section{Conclusion}

In conclusion, interactions of Nav channels with their partner proteins, such as ankG, are required for their proper concentration at the AIS and nodes of Ranvier. A number of important questions remain to be answered, like the mechanism of the interplay between neuronal activity and Nav channel concentration [34,47], and the in vivo relevance for several assembly and targeting mechanisms demonstrated using in vitro models. Hopefully, answering these questions will provide new therapeutic targets for diseases where misexpression and mislocalization of Nav channels cause functional impairments.

\section{Acknowledgments}

We would like to thank Hélène Vacher and Adele Woodhouse for discussions and critical reading of the manuscript.

\section{References}

[1] E.J. Arroyo, T. Xu, J. Grinspan, S. Lambert, S.R. Levinson, P.J. Brophy, E. Peles, S.S. Scherer, Genetic dysmyelination alters the molecular architecture of the nodal region, J. Neurosci. 22 (2002) 1726-1737.

[2] S. Basak, K. Raju, J. Babiarz, N. Kane-Goldsmith, D. Koticha, M. Grumet, Differential expression and functions of neuronal and glial neurofascin isoforms and splice variants during PNS development, Dev. Biol. 311 (2007) 408-422.

[3] V. Bennett, J. Healy, Membrane domains based on ankyrin and spectrin associated with cell-cell interactions, Cold Spring Harb. Perspect. Biol. 1 (2009) a003012.

[4] T. Boiko, M.N. Rasband, S.R. Levinson, J.H. Caldwell, G. Mandel, J.S. Trimmer, G. Matthews, Compact myelin dictates the differential targeting of two sodium channel isoforms in the same axon, Neuron 30 (2001) 91-104.

[5] T. Boiko, A. Van Wart, J.H. Caldwell, S.R. Levinson, J.S. Trimmer, G. Matthews, Functional specialization of the axon initial segment by isoform-specific sodium channel targeting, J. Neurosci. 23 (2003) 2306-2313.

[6] A. Brachet, C. Leterrier, M. Irondelle, M. Fache, V. Racine, J. Sibarita, D. Choquet, B. Dargent, Ankyrin G and protein kinase CK2 restrict sodium channel diffusion at the axonal initial segment before the establishment of the diffusion barrier, J. Cell Biol., in press.

[7] W.J. Brackenbury, J.D. Calhoun, C. Chen, H. Miyazaki, N. Nukina, F. Oyama, B. Ranscht, L.L. Isom, Functional reciprocity between $\mathrm{Na}^{+}$channel Nav1.6 and beta1 subunits in the coordinated regulation of excitability and neurite outgrowth, Proc. Natl. Acad. Sci. U.S.A. 107 (2010) 2283-2288.

[8] W.J. Brackenbury, T.H. Davis, C. Chen, E.A.Slat, M.J. Detrow, T.L. Dickendesher, B. Ranscht, L.L. Isom, Voltage-gated $\mathrm{Na}^{+}$channel beta1 subunit-mediated neurite outgrowth requires Fyn kinase and contributes to postnatal CNS development in vivo, J. Neurosci. 28 (2008) 3246-3256.

[9] A. Bréchet, M. Fache, A. Brachet, G. Ferracci, A. Baude, M. Irondelle, S. Pereira, C. Leterrier, B. Dargent, Protein kinase CK2 contributes to the organization of sodium channels in axonal membranes by regulating their interactions with ankyrin G, J. Cell Biol. 183 (2008) 1101-1114.

[10] J.H. Caldwell, K.L. Schaller, R.S. Lasher, E. Peles, S.R. Levinson, Sodium channel $\mathrm{Na}(\mathrm{v}) 1.6$ is localized at nodes of ranvier, dendrites, and synapses, Proc. Natl. Acad. Sci. U.S.A. 97 (2000) 5616-5620.

[11] W.A. Catterall, A.L. Goldin, S.G. Waxman, International Union of Pharmacology XLVII. Nomenclature and structure-function relationships of voltage-gated sodium channels, Pharmacol. Rev. 57 (2005) 397-409.

[12] C. Chen, V. Bharucha, Y. Chen, R.E. Westenbroek, A. Brown, J.D. Malhotra, D. Jones, C. Avery, P.J. Gillespie, K.A. Kazen-Gillespie, K. Kazarinova-Noyes, P. Shrager, T.L. Saunders, R.L. Macdonald, B.R. Ransom, T. Scheuer, W.A. Catterall, L.L. Isom, Reduced sodium channel density, altered voltage dependence of inactivation, and increased susceptibility to seizures in mice lacking sodium channel beta 2-subunits, Proc. Natl. Acad. Sci. U.S.A. 99 (2002) 17072-17077.

[13] C. Chen, R.E. Westenbroek, X. Xu, C.A. Edwards, D.R. Sorenson, Y. Chen D.P. McEwen, H.A. O'Malley, V. Bharucha, L.S. Meadows, G.A. Knudsen, A. Vilaythong, J.L. Noebels, T.L. Saunders, T. Scheuer, P. Shrager, W.A. Catterall, L.L. Isom, Mice lacking sodium channel beta1 subunits display defects in neuronal excitability, sodium channel expression, and nodal architecture, J. Neurosci. 24 (2004) 4030-4042.

[14] W. Ching, G. Zanazzi, S.R. Levinson, J.L. Salzer, Clustering of neuronal sodium channels requires contact with myelinating Schwann cells, J. Neurocytol. 28 (1999) 295-301.

[15] B.D. Clark, E.M. Goldberg, B. Rudy., Electrogenic tuning of the axon initial segment, Neuroscientist 15 (2009) 651-668.

[16] A.W. Custer, K. Kazarinova-Noyes, T. Sakurai, X. Xu, W. Simon, M. Grumet, P. Shrager, The role of the ankyrin-binding protein NrCAM in node of Ranvier formation, J. Neurosci. 23 (2003) 10032-10039.

[17] B. Dargent, F. Couraud, Down-regulation of voltage-dependent sodium channels initiated by sodium influx in developing neurons, Proc. Natl. Acad. Sci. U.S.A. 87 (1990) 5907-5911.

[18] B. Dargent, C. Paillart, E. Carlier, G. Alcaraz, M.F. Martin-Eauclaire, F. Couraud, Sodium channel internalization in developing neurons, Neuron 13 (1994) 683-690.

[19] J.Q. Davis, S. Lambert, V. Bennett, Molecular composition of the node of Ranvier: identification of ankyrin-binding cell adhesion molecules neurofascin (mucin+/third FNIII domain-) and NrCAM at nodal axon segments, J. Cell Biol. 135 (1996) 1355-1367.

[20] T.H. Davis, C. Chen, L.L. Isom, Sodium channel beta1 subunits promote neurite outgrowth in cerebellar granule neurons, J. Biol. Chem. 279 (2004) 51424-51432.

[21] J.J. Devaux, K.A. Kleopa, E.C. Cooper, S.S. Scherer, KCNQ2 is a nodal $\mathrm{K}^{+}$channel, J. Neurosci. 24 (2004) 1236-1244.

[22] J.J. Devaux, S.S. Scherer, Altered ion channels in an animal model of Charcot-Marie-Tooth disease type IA, J. Neurosci. 25 (2005) 1470-1480.

[23] A. Duflocq, B. Le Bras, E. Bullier, F. Couraud, M. Davenne, Nav1.1 is predominantly expressed in nodes of Ranvier and axon initial segments, Mol. Cell. Neurosci. 39 (2008) 180-192.

[24] Y. Dzhashiashvili, Y. Zhang, J. Galinska, I. Lam, M. Grumet, J.L. Salzer, Nodes of Ranvier and axon initial segments are ankyrin G-dependent domains that assemble by distinct mechanisms, J. Cell Biol. 177 (2007) 857-870.

[25] Y. Eshed, K. Feinberg, S. Poliak, H. Sabanay, O. Sarig-Nadir, I. Spiegel, J.R. Bermingham, E. Peles, Gliomedin mediates Schwann cell-axon interaction and the molecular assembly of the nodes of Ranvier, Neuron 47 (2005) 215229.

[26] M. Fache, A. Moussif, F. Fernandes, P. Giraud, J.J. Garrido, B. Dargent, Endocytotic elimination and domain-selective tethering constitute a potential mechanism of protein segregation at the axonal initial segment, J. Cell Biol. 166 (2004) 571-578.

[27] K. Feinberg, Y. Eshed-Eisenbach, S. Frechter, V. Amor, D. Salomon, H. Sabanay, J.L. Dupree, M. Grumet, P.J. Brophy, P. Shrager, E. Peles, A glial signal consisting of gliomedin and NrCAM clusters axonal $\mathrm{Na}^{+}$channels during the formation of nodes of Ranvier, Neuron 65 (2010) 490-502.

[28] A.B. Fotia, J. Ekberg, D.J. Adams, D.I. Cook, P. Poronnik, S. Kumar, Regulation of neuronal voltage-gated sodium channels by the ubiquitin-protein ligases Nedd4 and Nedd4-2, J. Biol. Chem. 279 (2004) 28930-28935.

[29] J.J. Garrido, F. Fernandes, P. Giraud, I. Mouret, E. Pasqualini, M.P. Fache, F. Jullien B. Dargent, Identification of an axonal determinant in the C-terminus of the sodium channel $\mathrm{Na}(\mathrm{v}) 1.2$, EMBO J. 20 (2001) 5950-5961.

[30] J.J. Garrido, F. Fernandes, A. Moussif, M. Fache, P. Giraud, B. Dargent, Dynamic compartmentalization of the voltage-gated sodium channels in axons, Biol. Cell 95 (2003) 437-445.

[31] J.J. Garrido, P. Giraud, E. Carlier, F. Fernandes, A. Moussif, M. Fache, D. Debanne, B. Dargent, A targeting motif involved in sodium channel clustering at the axonal initial segment, Science 300 (2003) 2091-2094.

[32] M. Goldfarb, J. Schoorlemmer, A. Williams, S. Diwakar, Q. Wang, X. Huang, J. Giza, D. Tchetchik, K. Kelley, A. Vega, G. Matthews, P. Rossi, D.M. Ornitz, E. D’Angelo, Fibroblast growth factor homologous factors control neuronal excitability through modulation of voltage-gated sodium channels, Neuron 55 (2007) 449-463.

[33] B. Gong, K.J. Rhodes, Z. Bekele-Arcuri, J.S. Trimmer, Type I and type II Na(+) channel alpha-subunit polypeptides exhibit distinct spatial and temporal patterning, and association with auxiliary subunits in rat brain, J. Comp. Neurol 412 (1999) 342-352.

[34] M.S. Grubb, J. Burrone, Activity-dependent relocation of the axon initial segment fine-tunes neuronal excitability, Nature 465 (2010) 1070-1074. 
[35] K.L. Hedstrom, M.N. Rasband, Intrinsic and extrinsic determinants of ion channel localization in neurons, J. Neurochem. 98 (2006) 1345-1352.

[36] K.L. Hedstrom, X. Xu, Y. Ogawa, R. Frischknecht, C.I. Seidenbecher, P. Shrager M.N. Rasband, Neurofascin assembles a specialized extracellular matrix at the axon initial segment, J. Cell Biol. 178 (2007) 875-886.

[37] A.S. Hill, A. Nishino, K. Nakajo, G. Zhang, J.R. Fineman, M.E. Selzer, Y. Okamura E.C. Cooper, Ion channel clustering at the axon initial segment and node of Ranvier evolved sequentially in early chordates, PLoS Genet. 4 (2008) e1000317.

[38] W. Hu, C. Tian, T. Li, M. Yang, H. Hou, Y. Shu., Distinct contributions of Na(v)1.6 and $\mathrm{Na}(\mathrm{v}) 1.2$ in action potential initiation and backpropagation, Nat. Neurosci. 12 (2009) 996-1002.

[39] M.C. Inda, J. DeFelipe, A. Muñoz, Voltage-gated ion channels in the axon initial segment of human cortical pyramidal cells and their relationship with chandelier cells, Proc. Natl. Acad. Sci. U.S.A. 103 (2006) 2920-2925.

[40] S.M. Jenkins, V. Bennett, Ankyrin-G coordinates assembly of the spectrin-based membrane skeleton, voltage-gated sodium channels, and L1 CAMs at Purkinje neuron initial segments, J. Cell Biol. 155 (2001) 739-746.

[41] S.M. Jenkins, V. Bennett, Developing nodes of Ranvier are defined by ankyrin$\mathrm{G}$ clustering and are independent of paranodal axoglial adhesion, Proc. Natl. Acad. Sci. U.S.A. 99 (2002) 2303-2308.

[42] M.R. Kaplan, M.H. Cho, E.M. Ullian, L.L. Isom, S.R. Levinson, B.A. Barres, Differential control of clustering of the sodium channels $\mathrm{Na}(\mathrm{v}) 1.2$ and $\mathrm{Na}(\mathrm{v}) 1.6$ at developing CNS nodes of Ranvier, Neuron 30 (2001) 105-119.

[43] M.R. Kaplan, A. Meyer-Franke, S. Lambert, V. Bennett, I.D. Duncan, S.R. Levinson, B.A. Barres, Induction of sodium channel clustering by oligodendrocytes, Nature 386 (1997) 724-728.

[44] K. Kazarinova-Noyes, J.D. Malhotra, D.P. McEwen, L.N. Mattei, E.O. Berglund, B. Ranscht, S.R. Levinson, M. Schachner, P. Shrager, L.L. Isom, Z.C. Xiao., Contactin associates with $\mathrm{Na}^{+}$channels and increases their functional expression, J. Neurosci. 21 (2001) 7517-7525.

[45] M. Komada, P. Soriano, [Beta]IV-spectrin regulates sodium channel clustering through ankyrin-G at axon initial segments and nodes of Ranvier, J. Cell Biol. 156 (2002) 337-348.

[46] G.J. Kress, S. Mennerick, Action potential initiation and propagation: upstream influences on neurotransmission, Neuroscience 158 (2009) 211-222.

[47] H. Kuba, Y. Oichi, H. Ohmori, Presynaptic activity regulates $\mathrm{Na}(+)$ channel distribution at the axon initial segment, Nature 465 (2010) 1075-1078.

[48] S. Lacas-Gervais, J. Guo, N. Strenzke, E. Scarfone, M. Kolpe, M. Jahkel, P. De Camilli, T. Moser, M.N. Rasband, M. Solimena, BetaIVSigma1 spectrin stabilizes the nodes of Ranvier and axon initial segments, J. Cell Biol. 166 (2004) 983-990.

[49] F. Laezza, B.R. Gerber, J. Lou, M.A. Kozel, H. Hartman, A.M. Craig, D.M. Ornitz J.M. Nerbonne, The FGF14(F145S) mutation disrupts the interaction of FGF14 with voltage-gated $\mathrm{Na}^{+}$channels and impairs neuronal excitability, J. Neurosci. 27 (2007) 12033-12044.

[50] S. Lambert, J.Q. Davis, V. Bennett, Morphogenesis of the node of Ranvier: co-clusters of ankyrin and ankyrin-binding integral proteins define early developmental intermediates, J. Neurosci. 17 (1997) 7025-7036.

[51] G. Lemaillet, B. Walker, S. Lambert, Identification of a conserved ankyrinbinding motif in the family of sodium channel alpha subunits, J. Biol. Chem. 278 (2003) 27333-27339.

[52] A. Lorincz, Z. Nusser, Cell-type-dependent molecular composition of the axon initial segment, J. Neurosci. 28 (2008) 14329-14340.

[53] A. Lorincz, Z. Nusser, Molecular identity of dendritic voltage-gated sodium channels, Science 328 (2010) 906-909.

[54] J.D. Malhotra, K. Kazen-Gillespie, M. Hortsch, L.L. Isom, Sodium channel beta subunits mediate homophilic cell adhesion and recruit ankyrin to points of cell-cell contact, J. Biol. Chem. 275 (2000) 11383-11388.

[55] P. Martin, M. Carnaud, G. Garcia del Caño, M. Irondelle, T. Irinopoulou, J. Girault, B. Dargent, L. Goutebroze, Schwannomin-interacting protein-1 isoform IQCJ SCHIP-1 is a late component of nodes of Ranvier and axon initial segments, J. Neurosci. 28 (2008) 6111-6117.

[56] D.P. McEwen, L.L. Isom, Heterophilic interactions of sodium channel beta1 subunits with axonal and glial cell adhesion molecules, J. Biol. Chem. 279 (2004) 52744-52752.

[57] C.V. Melendez-Vasquez, J.C. Rios, G. Zanazzi, S. Lambert, A. Bretscher, J.L. Salzer, Nodes of Ranvier form in association with ezrin-radixin-moesin (ERM)positive Schwann cell processes, Proc. Natl. Acad. Sci. U.S.A. 98 (2001) 12351240.

[58] T. Murakami, A. Ohtsuka, Perisynaptic barrier of proteoglycans in the mature brain and spinal cord, Arch. Histol. Cytol. 66 (2003) 195-207.

[59] C. Nakada, K. Ritchie, Y. Oba, M. Nakamura, Y. Hotta, R. Iino, R.S. Kasai, K. Yamaguchi, T. Fujiwara, A. Kusumi, Accumulation of anchored proteins forms membrane diffusion barriers during neuronal polarization, Nat. Cell Biol. 5 (2003) 626-632.

[60] I. Ogiwara, H. Miyamoto, N. Morita, N. Atapour, E. Mazaki, I. Inoue, T. Takeuchi, S. Itohara, Y. Yanagawa, K. Obata, T. Furuichi, T.K. Hensch, K. Yamakawa, Na(v)1.1 localizes to axons of parvalbumin-positive inhibitory interneurons: a circuit basis for epileptic seizures in mice carrying an Scn1a gene mutation, J. Neurosci. 27 (2007) 5903-5914.

[61] N. Osorio, L. Cathala, M.H. Meisler, M. Crest, J. Magistretti, P. Delmas, Persistent Nav1.6 current at axon initial segments tunes spike timing of cerebellar granule cells, J. Physiol. (Lond.) 588 (2010) 651-670.

[62] Z. Pan, T. Kao, Z. Horvath, J. Lemos, J. Sul, S.D. Cranstoun, V. Bennett, S.S. Scherer, E.C. Cooper, A common ankyrin-G-based mechanism retains KCNQ and Nav channels at electrically active domains of the axon, J. Neurosci. 26 (2006) 2599-2613.
[63] G.A. Patino, L.L. Isom, Electrophysiology and beyond: multiple roles of $\mathrm{Na}(+)$ channel beta subunits in development and disease [Internet], Neurosci. Lett. (2010) [cité 2010] Available from: http://www.ncbi.nlm.nih. gov/pubmed/20600605.

[64] R. Planells-Cases, M. Caprini, J. Zhang, E.M. Rockenstein, R.R. Rivera, C. Murre, E. Masliah, M. Montal, Neuronal death and perinatal lethality in voltage-gated sodium channel alpha(II)-deficient mice, Biophys. J. 78 (2000) 2878-2891.

[65] S. Poliak, L. Gollan, D. Salomon, E.O. Berglund, R. Ohara, B. Ranscht, E. Peles, Localization of Caspr2 in myelinated nerves depends on axon-glia interactions and the generation of barriers along the axon, J. Neurosci. 21 (2001) 75687575.

[66] C. Politi, D. Del Turco, J.M. Sie, P.A. Golinski, I. Tegeder, T. Deller, C. Schultz, Accumulation of phosphorylated I kappaB alpha and activated IKK in nodes of Ranvier, Neuropathol. Appl. Neurobiol. 34 (2008) 357-365.

[67] Y. Qu, R. Curtis, D. Lawson, K. Gilbride, P. Ge, P.S. DiStefano, I. Silos-Santiago, W.A. Catterall, T. Scheuer, Differential modulation of sodium channel gating and persistent sodium currents by the beta1, beta2, and beta3 subunits, Mol. Cell. Neurosci. 18 (2001) 570-580.

[68] M.N. Rasband, E. Peles, J.S. Trimmer, S.R. Levinson, S.E. Lux, P. Shrager, Dependence of nodal sodium channel clustering on paranodal axoglial contact in the developing CNS, J. Neurosci. 19 (1999) 7516-7528.

[69] C.F. Ratcliffe, Y. Qu, K.A. McCormick, V.C. Tibbs, J.E. Dixon, T. Scheuer, W.A. Catterall, A sodium channel signaling complex: modulation by associated receptor protein tyrosine phosphatase beta, Nat. Neurosci. 3 (2000) 437-444.

[70] C.F. Ratcliffe, R.E. Westenbroek, R. Curtis, W.A. Catterall, Sodium channel beta1 and beta3 subunits associate with neurofascin through their extracellular immunoglobulin-like domain, J. Cell Biol. 154 (2001) 427-434.

[71] F. Rieger, M. Pinçon-Raymond, A. Lombet, G. Ponzio, M. Lazdunski, R.L. Sidman, Paranodal dysmyelination and increase in tetrodotoxin binding sites in the sciatic nerve of the motor end-plate disease (med/med) mouse during postnatal development, Dev. Biol. 101 (1984) 401-409.

[72] J.C. Rios, M. Rubin, M. St Martin, R.T. Downey, S. Einheber, J. Rosenbluth, S.R. Levinson, M. Bhat, J.L. Salzer, Paranodal interactions regulate expression of sodium channel subtypes and provide a diffusion barrier for the node of Ranvier, J. Neurosci. 23 (2003) 7001-7011.

[73] J. Rosenbluth, Intramembranous particle distribution at the node of Ranvier and adjacent axolemma in myelinated axons of the frog brain, J. Neurocytol. 5 (1976) 731-745.

[74] J. Rosenbluth, J.L. Dupree, B. Popko, Nodal sodium channel domain integrity depends on the conformation of the paranodal junction, not on the presence of transverse bands, Glia 41 (2003) 318-325.

[75] J.L. Salzer, Polarized domains of myelinated axons, Neuron 40 (2003) 297-318

[76] J.L. Salzer, P.J. Brophy, E. Peles, Molecular domains of myelinated axons in the peripheral nervous system, Glia 56 (2008) 1532-1540.

[77] C. Schultz, H. König, D. Del Turco, C. Politi, G.P. Eckert, E. Ghebremedhin, J.H.M. Prehn, D. Kögel, T. Deller, Coincident enrichment of phosphorylated IkappaBalpha, activated IKK, and phosphorylated p65 in the axon initial segment of neurons, Mol. Cell. Neurosci. 33 (2006) 68-80.

[78] D.L. Sherman, S. Tait, S. Melrose, R. Johnson, B. Zonta, F.A. Court, W.B. Macklin, S. Meek, A.J.H. Smith, D.F. Cottrell, P.J. Brophy, Neurofascins are required to establish axonal domains for saltatory conduction, Neuron 48 (2005) 737742 .

[79] E. Shirahata, H. Iwasaki, M. Takagi, C. Lin, V. Bennett, Y. Okamura, K. Hayasaka, Ankyrin-G regulates inactivation gating of the neuronal sodium channel, Nav1. 6, J. Neurophysiol. 96 (2006) 1347-1357.

[80] J. Srinivasan, M. Schachner, W.A. Catterall, Interaction of voltage-gated sodium channels with the extracellular matrix molecules tenascin- $C$ and tenascin- $R$, Proc. Natl. Acad. Sci. U.S.A. 95 (1998) 15753-15757.

[81] Y. Srinivasan, L. Elmer, J. Davis, V. Bennett, K. Angelides, Ankyrin and spectrin associate with voltage-dependent sodium channels in brain, Nature 333 (1988) $177-180$.

[82] K. Susuki, M.N. Rasband, Molecular mechanisms of node of Ranvier formation, Curr. Opin. Cell Biol. 20 (2008) 616-623.

[83] A. Suzuki, T. Hoshi, T. Ishibashi, A. Hayashi, Y. Yamaguchi, H. Baba., Paranodal axoglial junction is required for the maintenance of the Nav1.6-type sodium channel in the node of Ranvier in the optic nerves but not in peripheral nerve fibers in the sulfatide-deficient mice, Glia 46 (2004) 274-283.

[84] H. Vacher, D.P. Mohapatra, J.S. Trimmer, Localization and targeting of voltagedependent ion channels in mammalian central neurons, Physiol. Rev. 88 (2008) 1407-1447.

[85] A. Van Wart, G. Matthews, Impaired firing and cell-specific compensation in neurons lacking nav1.6 sodium channels, J. Neurosci. 26 (2006) 7172-7180.

[86] A. Van Wart, G. Matthews, Expression of sodium channels Nav1.2 and Nav1.6 during postnatal development of the retina, Neurosci. Lett. 403 (2006) 315317.

[87] A. Van Wart, J.S. Trimmer, G. Matthews, Polarized distribution of ion channels within microdomains of the axon initial segment, J. Comp. Neurol. 500 (2007) 339-352.

[88] A.V. Vega, D.L. Henry, G. Matthews, Reduced expression of $\mathrm{Na}(\mathrm{v}) 1.6$ sodium channels and compensation by $\mathrm{Na}(\mathrm{v}) 1.2$ channels in mice heterozygous for a null mutation in Scn8a, Neurosci. Lett. 442 (2008) 69-73.

[89] M.G. Voas, T.D. Glenn, A.R. Raphael, W.S. Talbot, Schwann cells inhibit ectopic clustering of axonal sodium channels, J. Neurosci. 29 (2009) 14408-14414.

[90] R.E. Westenbroek, D.K. Merrick, W.A. Catterall, Differential subcellular localization of the RI and RII $\mathrm{Na}^{+}$channel subtypes in central neurons, Neuron 3 (1989) 695-704. 
[91] B. Winckler, P. Forscher, I. Mellman, A diffusion barrier maintains distribution of membrane proteins in polarized neurons, Nature 397 (1999) 698-701.

[92] E.K. Wittmack, A.M. Rush, M.J. Craner, M. Goldfarb, S.G. Waxman, S.D. Dib-Hajj, Fibroblast growth factor homologous factor 2B: association with Nav1.6 and selective colocalization at nodes of Ranvier of dorsal root axons, J. Neurosci. 24 (2004) 6765-6775.

[93] Z.C. Xiao, D.S. Ragsdale, J.D. Malhotra, L.N. Mattei, P.E. Braun, M. Schachner, L.L. Isom, Tenascin-R is a functional modulator of sodium channel beta subunits, J. Biol. Chem. 274 (1999) 26511-26517.

[94] X. Xu, P. Shrager, Dependence of axon initial segment formation on $\mathrm{Na}^{+}$channel expression, J. Neurosci. Res. 79 (2005) 428-441.

[95] Y. Yang, S. Lacas-Gervais, D.K. Morest, M. Solimena, M.N. Rasband, BetaIV spectrins are essential for membrane stability and the molecular organization of nodes of Ranvier, J. Neurosci. 24 (2004) 7230-7240.
[96] Y. Yang, Y. Ogawa, K.L. Hedstrom, M.N. Rasband, betaIV spectrin is recruited to axon initial segments and nodes of Ranvier by ankyrinG, J. Cell Biol. 176 (2007) 509-519.

[97] X. Zhang, V. Bennett, Restriction of $480 / 270-\mathrm{kD}$ ankyrin G to axon proximal segments requires multiple ankyrin G-specific domains, J. Cell Biol. 142 (1998) 1571-1581.

[98] D. Zhou, S. Lambert, P.L. Malen, S. Carpenter, L.M. Boland, V. Bennett, Ankyring is required for clustering of voltage-gated Na channels at axon initial segments and for normal action potential firing, J. Cell Biol. 143 (1998) 12951304 .

[99] B. Zonta, S. Tait, S. Melrose, H. Anderson, S. Harroch, J. Higginson, D.L. Sherman, P.J. Brophy, Glial and neuronal isoforms of Neurofascin have distinct roles in the assembly of nodes of Ranvier in the central nervous system, J. Cell Biol. 18 (2008) 1169-1177. 